library experience/understanding the students have, as well as the major areas of insecurity or concern for individual students.

Survey answers can also tell you, directly or indirectly, some useful things about your library. For example, if students can't find the reference desk, is signage adequate? Should there be a better map of the library? If students feel ignored even if they ask for help, is overall service what it should be? Are student assistants misdirecting people? Are there some personnel who are less than helpful? Should instructions for automated equipment, the cata$\log$, individual service locations be more clear?

In an anonymous survey, students often tell you more than you asked to know; comments often come more from personal feelings and individual experiences than as a direct answer to your survey questions. You may also begin to identify faculty who give the library short shrift or bad press, since students often absorb teachers' peeves and biases by osmosis. Such evidence can be useful in spurring some action on the part of the library to address faculty problems - or problem faculty. Sometimes a simple update will do; sometimes re-education may be necessary, especially for some who have not gotten any of your library's dust on their feet since the last revision of their lecture notes twenty years ago.

Careful writing of the survey can give forth statistics useful to the BI program, and to the library as a whole. If a computer program were written to correlate elements of the individual survey forms, good statistical evidence supporting a BI program might emerge. For example, the number and type of problems encountered could be correlated to the number, level, or absence of previous BI lectures or tours; student level might be correlated with attitude, evaluation of lectures, or type of problems encountered. [If anyone has, and is willing to share such a computer program, please let me-and the editor of $C \Downarrow R L$ News-know!]

Of course, anonymous surveys and evaluations have their drawbacks; some students will tell things on an anonymous written form that they would never tell in person - which obviously has its repercussions in the form of spurious, comic, or deviant comments. But sometimes students have creative insights that can cut through academic insulation - and that fog of professional prejudiceby-habit.

Best of all, using a survey's results at the beginning of your lecture is a good way to gain confidence (you're not coming at them cold); to get attention; to give the class the feeling (one would hope, based in reality) that you care about their individual problems; and to keep them listening for the solution to the problem they wrote aboutwhich your talk probably would have addressed in any case, but which now is perceptively tailored to your audience as individuals.

\title{
Innovative use of in-house current awareness profiles as a guide for collection development in a pharmaceutical library
}

\author{
By Daniel T. Law \\ Senior Information Specialist \\ Smith Kline \& French Laboratories, King of Prussia, Pa.
}

If the basic tenor of collection development (CD) is the identification and procurement of resources in support of current and anticipated patron needs, then it becomes the primary responsibility of the CD librarian to first assess those needs, and then to select and acquire resources for the meeting of those needs. However, CD librarians are often met with distrust, particularly from faculty colleagues who often are mildly suspicious of their qualifications as "book selectors" ("Are they really qualified?"), or their "methods of selection" ("How do they choose their books anyway?"). The problem stems largely from the imprecise nature of their work. Granted, CD is not an exact science; but it need not become an entirely subjective and arbitrary undertaking either.

Perhaps what is needed is a heightened awareness on the part of collection developers to put CD on a more objective and "scientific" foundation. Such a feat is not as impossible as it may appear. Collection development has at least two attributes which qualify it as "scientific." They are: controllability and quantifiability. Collection development is controllable, to the extent that its activities can be efficiently directed towards the attainment of desired objectives. ${ }^{1}$ It is quantifiable, because

${ }^{1}$ R. L. Ackoff, et al., Scientific Method: Optimizing Applied Research Decisions (New York: John Wiley \& Sons, 1962), 3. 
such directed activities can be monitored numerically, and the attainment of collection objectives can be measured quantitatively, if not qualitatively.

As an attempt to put $\mathrm{CD}$ on a more controlled and quantitative basis, the Research and Development Library of Smith Kline \& French Laboratories has adopted an innovative approach. Key words and key phrases from in-house current awareness profiles are structured into hierarchical subject categories reflecting the research emphases of the company. The resultant Collection Development Guide serves the dual function of: 1) an empirical guide for the selection of books, and 2) an Acquisition Record for keeping track of collection activities.

\section{Description of CD Guide}

The current awareness program at Smith Kline \& French Laboratories consists of, in large part, a contracted service with the Institute for Scientific Information (ISI) in Philadelphia. Over 76 ASCA (Automated Subject Citation Alert) and ASCA Topic profiles are now being maintained, covering all areas of interest to research and development. In constructing the CD Guide, key words and key phrases from these profiles are compiled and classified into a somewhat hierarchical scheme, consisting of 13 major subjects, such as molecular biology, tumor, gastrointestinal, anti-infectives, etc. Under each major subject, key words and key phrases from various profiles are further grouped together into sub-categories. The subjects of gastrointestinal and pharmaceutics/drug design are reproduced on the previous page as an illustration.

In actual practice, a fresh copy of this Guide is used each month to record acquisition transactions for the month. Whenever a title is ordered under a particular subject, its listed price is entered in the space provided next to the appropriate category. If the title happens to be a reference work, its cost is then circled in red. At the end of each month, expenditure by subjects and types of books ordered (i.e., reference vs. non-reference) can then be readily tallied and obtained.

\section{Summary}

By using this simple Guide, we have found the following purposes served:

1. With the use of this instrument, $C D$ has become to us a purposeful and targeted activity guided by parameters derived from the objective analysis of research directions and interests of the company.

2. The use of this Guide as an acquisition record also permits the tracking of monthly expenditure by subjects and types of books ordered. This in turn provides us with the basis for program-monitoring, since collection efforts are now traceable by subjects and costs.

3. Furthermore, the adoption of this approach to CD has successfully allowed us to put an essentially subjective activity as $\mathrm{CD}$ on a more objective and scientific foundation, thus making the selling of the $\mathrm{CD}$ concept to our research/scientific community a much easier task.

\section{Standards for archival description}

The Working Group on Standards for Archival Description, a project funded by a grant from the National Historical Publications and Records Commission and sponsored by Harvard University, held its first meeting December 3-4, 1988, at the University of Maryland, College Park.

Several concerned activists initiated the project when they recognized an increasing desire in the archival community for standardized descriptive practices and a growing frustration over the absence of systematic procedures for developing or evaluating such standards. The rapidly growing number of archival institutions that are developing internal information systems or participating in networks has only increased the intensity of interest in and need for clarification of standards-related issues.

At its meeting the group discussed the nature of archival description and how its processes and products might be affected, both positively and negatively, by the development, formal adoption, and widespread use of standards. It acknowledged that standards are not ends in themselves but means to improve professional practice. While standards could be pursued in many areas, some might be too expensive or cumbersome to implement or consensus among affected individuals or institutions might be impossible to achieve.

Standards specific to archival description can be developed at four levels. Information systems standards, the broadest, might define the components of a repository's total descriptive program. Data structure standards establish what elements of information are included in a particular type of descriptive product, such as a MARC record or repository guide. Data content standards specify what rules apply to the language used in any given element. The narrowest, data value standards, are lists of standard terms to be used within a specific element (e.g., authority lists).

The working group also developed a list of ten criteria against which to measure the desirability of adopting existing standards, creating new ones, or influencing their development outside the archival 
profession. The criteria include considerations such as cost-effectiveness, immediacy of the need or effect, and breadth of applicability.

Members of the working group, chaired by Lawrence Dowler, are now preparing background or informational papers on several topics raised before the group reconvenes in June. The issues addressed will include the potential for developing guidelines or conventions for archival information systems, the impact of format integration on archival uses of the MARC format, and the relationship between description standards activities in the U.S. and Canada. For more information, contact Victoria Walch, $65 \mathrm{~N}$. Westminster St., Iowa City, IA 52245; (319) 338-6650.

\title{
Online search services
}

\section{in the community college}

\author{
By Wanda K. Johnston \\ Director of Learning Resources \\ Morton College
}

\section{Online services can improve the LRC's image.}

\section{I}

n 1977 the American Library Association passed a resolution promoting equal access to information. This resolution states in part that "It shall be the policy of the American Library Association to seek to make it possible for library and information science agencies which receive their major support from public funds to provide service to all people without additional fees and to utilize the latest technological developments to ensure the best possible access to information." 1

Academic libraries in the United States are suffering from severe economic pressure due to tightened budgets and coupled with rapidly increasing costs. Tuition revenue and enrollments are declining. State and federal assistance has decreased. Local tax referenda are increasingly difficult to pass. Some costs, such as those for facilities and tenured

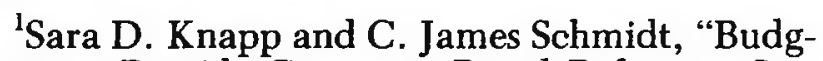
eting to Provide Computer-Based Reference Services: A Case Study." Journal of Academic Librarianship 5 (March 1979): 9.
}

faculty, are relatively fixed compared to enrollment, necessitating budget cuts in other areas, such as libraries. Academic library budgets are rising more slowly than overall university budgets and definitely more slowly than information costs. ${ }^{2}$

How are academic libraries, specifically community college libraries, responding to the ALA policy of equal access to information during this period of economic decline? A review of the literature, combined with a survey of the membership of the Northern Illinois Learning Resources Cooperative, provides more information.

Among published individual case studies, three describe successful free online services. The Library at California State College considers online services an integral part of the total reference service; consequently, online search services are not treated any differently from any other reference

${ }^{2}$ Donald W. King, "Pricing Policies in Academic Libraries," Library Trends 28 (Summer 1979): 47-62. 